\title{
A AÇÃO POPULAR NO ORDENAMENTO JURÍDICO BRASILEIRO: DE SUA ORIGEM AOS SEUS ATUAIS PONTOS DE INFLEXÃO ${ }^{1}$
}

\section{Larissa Clare Pochmann da Silva ${ }^{2}$}

\section{Resumo}

$\mathrm{O}$ artigo analisa a ação popular no ordenamento jurídico brasileiro, de sua origem até a atualidade, quando enfatiza três pontos de inflexão na trajetória desta garantia constitucional. Procura-se, na origem, demonstrar como a previsão brasileira se afasta do berço do instituto, a actio popularis romana, e, na atualidade, refutar os mitos de que as ações populares seriam malsucedidas; de que este instrumento seria menos relevante do que a ação civil pública e de que muitas ações populares são ajuizadas de má-fé.

Palavras-Chave: Ação Popular; Histórico; Direitos Transindividuais; Pontos de Inflexão

\section{INTRODUÇÃO}

O presente trabalho, através de pesquisa bibliográfica e empírica, a que é atribuída o tratamento de uma abordagem qualitativa, traça uma evolução histórica da ação popular para, hodiernamente, apontar como, em torno de seu delineamento, construíram-se alguns mitos, que apenas servem para tentar desprestigiar o instituto. Refere-se como mitos s afirmações de que as ações populares seriam malsucedidas; de que este instrumento seria menos relevante do que a ação civil pública e de que muitas ações populares são ajuizadas de má-fé.

A fim de cumprir esse mister, inicia-se abordando o berço da ação popular em Roma, com ênfase em seu cabimento e, em seguida, trata-se da evolução histórica desse instrumento no Brasil, para explicitar como a feição assumida aqui se distancia de sua origem romana.

Após, aponta-se a problemática dos direitos transindividuais, cuja compreensão é relevante diante do objeto tutelado pela ação popular e, por fim, analisam-se os três referidos mitos, escolhidos em virtude de sua frequente menção na prática, para tentar que o tema alcance seu devido destaque.

\footnotetext{
1 Os dados da ação popular referentes à Justiça Federal de São Paulo estão disponíveis em Disponível em http://www.jfsp.jus.br/assets/Uploads/administrativo/NUCS/revista/revista22/JR0022.pdf. Acesso em 01 nov. 2016.

2 Professora no curso de graduação e de pós-graduação lato sensu da Universidade Candido Mendes (UCAM). Doutora em Direito pela Universidade Estácio de Sá (UNESA). Membro do Instituto Brasileiro de Direito Processual (IBDP), da Associação Brasileira de Direito Processual (ABDPro) e da Rede de Pesquisa Empírica (REED). E-mail: larissacpsilva@gmail.com
} 


\section{A ORIGEM DA AÇÃO POPULAR}

O direito romano é considerado, por alguns estudiosos (MANCUSO, 2003, p. 42; LEONEL, 2002, p. 42; SIDOU, 1998, p. 303-317), o marco da tutela coletiva, referindo-se, especificamente, ao berço da ação popular. Em Roma, a concepção de Estado ainda não estava bem delineada, mas havia um forte vínculo entre o cidadão e a proteção da coisa pública. Prevalecia a ideia de que a res publica pertenceria ao cidadão romano e, por isso, cada um poderia pleitear tutelá-la em juízo. Porém, estava excluída a legitimidade das mulheres e dos menores, salvo se fosse demonstrado um excepcional interesse no caso concreto (LEONEL, 2002, p. 45).

A actio popularis romana não se situava nem no campo do interesse privado, nem propriamente no interesse público, sendo que a maioria possuía natureza penal, semelhante às atuais contravenções, com a cominação de pena pecuniária. As pouco frequentes demandas de natureza cível muito se assemelham hoje às ações cominatórias ou aos interditos proibitórios (MANCUSO, 2003, p. 45).

Não há um consenso sobre todas as suas classificações, mas era possível se obter, a defesa de coisas públicas ou de caráter sacro (LEONEL, 2002, p. 45), sendo admitida a tutela em face de violadores de sepultura; em face de quem atirasse objetos em via pública; contra quem, perigosamente, mantivesse objetos em sacada ou na beira de telhado; contra quem alterasse o edito do pretor; para impedir que animais fossem a locais frequentados pelo público; contra os que deslocassem pedras demarcadoras de propriedades; para impedir que o herdeiro abrisse a sucessão em caso de morte violenta do autor da herança, sem antes apurar a responsabilidade em virtude da falha dos servos dos servos no dever de defender o falecido; para se obter a liberdade de um escravo ou para o habeas corpus; em caso de conluio entre escravos e seus antigos donos, se declarassem que estes haviam nascido livres; para a proteção de tutelados e de curatelados e para a restituição de somas perdidas em jogo (MANCUSO, 2003, p. 45-46).

O sentido original das ações populares romanas parece, porém, ter se perdido no direito intermediário, já que a simbiose entre cidadão e Estado não prosperava durante a Idade Média, com o regime feudal, ou durante as monarquias absolutistas (ALMEIDA, 2007, p. 346). O instrumento só foi ressurgir na Bélgica, com um perfil distinto, com a lei comunal de 30 de março de 1836, seguida pela lei comunal francesa de 1837 e, em matéria eleitoral, pelas leis italianas de 20 de setembro e 26 de outubro de 1859 (RAMOS, 1991, p. 346).

\section{A PREVISÃO DA AÇÃO POPULAR NO ORDENAMENTO JURÍDICO BRASILEIRO E O AFASTAMENTO DO MODELO DAS AÇÕES POPULARES ROMANAS}

No Brasil, a ação popular é considerada o marco da tutela coletiva, através disposição do artigo 113, n. 38, 
da Constituição da República de 1934, ao possibilitar que qualquer cidadão pleiteasse a declaração de nulidade ou anulação de ato lesivo ao patrimônio da União, dos Estados ou dos Municípios. Antes, a Constituição de 1824, no artigo 157, limitava-se a tratar da ação popular penal, que não mais subsiste e nem é retratada pela doutrina como mecanismo para a atuação na tutela coletiva.

Porém, não apenas essa disposição logo acabou retirada do ordenamento jurídico brasileiro, como a regulamentação do instrumento processual ocorreu apenas anos mais tarde. A previsão da ação popular foi suprimida pela Constituição de 1937, sendo reintroduzida pela Carta de 1946, no artigo 141, \$38, e regulamentada pela Lei no 4.717/1965, denominada Lei da Ação Popular, mantendo, a partir deste momento, sua previsão em todas as Constituições seguintes.

A referida lei fixou o conceito de patrimônio em seu artigo $1^{\circ}, \$ 1^{\circ}$, admitindo o pleito de invalidação não apenas quando houvesse prejuízo pecuniário, mas, também, quando fossem lesados bens imateriais ou não suscetíveis de avaliação monetária (BARBOSA MOREIRA, 2014, p. 28). Esta redação foi ampliada em 1977, por ocasião da Lei no 6.513, para abranger os bens de valor turístico no artigo $1^{\circ}$, $\$ 1^{\circ}$ da Lei no $4.717 / 1965$.

O artigo 11 da Lei no 4.717/1965 consagrou uma sentença complexa, com uma natureza constitutiva negativa ou declaratória e, em decorrência da procedência, condenatória, devendo os responsáveis o pagamento de perdas e danos.

A Lei da Ação Popular estendeu, ainda, a redação do artigo 141, \$ 38 da Constituição de 1946, em vigor na época de seu advento, que só incluía atos lesivos ao patrimônio da União, dos Estados, dos Municípios, das entidades autárquicas e das sociedades de economia mista. Foi incluída a tutela do patrimônio "de sociedades mútuas de seguro nas quais a União represente os segurados ausentes, de empresas públicas, de serviços sociais autônomos, de instituições ou fundações para cuja criação ou custeio o tesouro público haja concorrido ou concorra com mais de cinquenta por cento do patrimônio ou da receita ânua, de empresas incorporadas ao patrimônio da União, do Distrito Federal, dos Estados e dos Municípios, e de quaisquer pessoas jurídicas ou entidades subvencionadas pelos cofres públicos".

Mais tarde, a Constituição de 1967, no artigo 150, \$ 31 não reproduziu a redação ampliada pela Lei no 4.717/65 em relação aos entes com patrimônio tutelável pela ação popular, tendo sua previsão constitucional se alterado em 1988.

A Constituição de 1988, no artigo 5º inciso LXXIII, além de isentar de custas a ação popular, não recepcionando o artigo 10 da Lei no 4.717/1965, alargou o cabimento do instituto (BARBOSA MOREIRA, 1991, p. 192), para abranger a moralidade administrativa e o meio ambiente.

Afirma-se que o desenho da ação popular brasileira revalidou a actio popularis romana ao permitir a tutela da moralidade administrativa, do meio ambiente e do patrimônio histórico e cultural (MANCUSO, 2003, 
p. 46), mas parece-nos que a ação popular, apesar de sua origem remota romana, nitidamente sofreu significativas alterações até a atualidade, tecendo-se duas considerações sobre o tema.

A primeira se refere ao próprio desenvolvimento da teoria constitucional e da relação entre cidadão e Estado. Em Roma, a atuação do cidadão não era a partir de um viés de uma sociedade de direitos, tal como se instala a partir dos movimentos constitucionalistas no século XX, mas sim uma atuação movida por se destacar socialmente (SILVA, 2013, p. 5). O Estado Democrático de Direito contém, em sua ideia, dentre outras garantias, o reconhecimento de direitos e liberdades e o controle do exercício do poder estatal mediante instrumentos jurídicos constitucionalmente determinados. Nesta perspectiva, a ação popular se revela como um instrumento típico da cidadania (MENDES; BRANCO, 2014, p. 416).

A segunda consideração é que, ao contrário da maioria das actio popularis romanas, a ação popular brasileira não possui um caráter penal, situando-se como um direito público subjetivo do indivíduo, uma garantia em face do Estado, com a possibilidade de sua participação ao fiscalizar os atos da Administração.

\section{OS DIREITOS TRANSINDIVIDUAIS}

A partir da regulamentação da ação popular em 1965 no Brasil, o estudo dos direitos coletivos ou difusos surgiu e floresceu na Itália na década de 70, sendo discutido no Congresso de Pavia em 1974 por, dentre outros estudiosos, Denti, Cappelletti, Proto Pisani, Vigoriti e Trocker. Destacaram-se a indeterminabilidade de sua titularidade e a indivisibilidade em relação ao objeto, colocados no meio do caminho entre o público e o privado, próprios de uma sociedade de conflitos de massa (GRINOVER, 2000, p. 9-15).

Foi com o trabalho de José Carlos Barbosa Moreira, publicado inicialmente em 1979, na obra, Studi in onore di Enrico Tullio Liebman, que a atenção brasileira efetivamente se voltou para a proteção dos direitos coletivos em sentido amplo, sejam eles difusos, coletivos ou individuais homogêneos, e para a sua proteção judicial.

Barbosa Moreira logrou estabelecer a tipologia dos interesses supraindividuais. Ele destacou o tema através de interesses indivisíveis, os essencialmente coletivos (lato sensu), e divisíveis, os acidentalmente coletivos (BARBOSA MOREIRA, 1991, p .188-189), sendo o tema, em seguida, explorado no Brasil por Ada Pellegrini Grinover e por Waldemar Mariz de Oliveira Jr., dentre outros (MENDES, 2014, p. 201).

Em 1990, o Código de Defesa do Consumidor (CDC) teve grande destaque enquanto um modelo estrutural para as ações coletivas, não se limitando à proteção do consumidor em juízo, ao regular os aspectos mais importantes da tutela coletiva, em uma aplicação integrada à tutela coletiva (ALMEIDA, 2007, p. 20). Foi, ainda, o artigo 81, parágrafo único, do CDC que trouxe a previsão de que a defesa coletiva em juízo será exercida quando se tratar de direitos ou interesses difusos (inciso I), coletivos (inciso II) ou individuais homogêneos (inciso III), 
definindo estes direitos.

Porém, a falta de clareza da distinção entre os direitos difusos e coletivos e os equívocos cometidos na caracterização dos fatos vêm causando confusão na doutrina e na jurisprudência (MENDES; SILVA, 2014, p. 1.072-1.074). Barbosa Moreira já havia alertado que direitos difusos e coletivos são expressões que "durante muito tempo foram usadas, e não apenas no Brasil, em forma, por assim dizer, promíscua, isto é, sem preocupação nítida entre os dois conceitos" (MILARÉ (coord.), 1995, p. 188).

A meta-individualidade caracteriza os direitos difusos, mas nem todos os interesses meta-individuais são difusos. Como destaca Ada Pellegrini Grinover, os interesses difusos possuem ampla área de conflittualitá (GRINOVER, 2014, p. 42). Algumas pretensões às vezes recebem a qualificação errônea de direitos difusos ou coletivos, mas a simples formulação de pedido(s) comum(ns) não significa que não haja a possibilidade de fracionamento da solução. A distinção entre direitos difusos e coletivos abrange, segundo a explicação de Aluisio Gonçalves de Castro Mendes (MENDES, 2014, p. 221-222), dois aspectos: um aspecto subjetivo e outro objetivo.

O primeiro aspecto, subjetivo, diz respeito à transindividualidade, ou seja, está além do indivíduo, no sentido de que não the pertence com exclusividade, mas, sim, a uma pluralidade de pessoas, que poderão ser, conforme sejam os interesses difusos ou coletivos, respectivamente, indeterminadas ou determinadas, bem como ligadas por circunstâncias de fato ou por uma relação jurídica base. Há, portanto, identidade quanto à transindividualidade, mas distinção no que diz respeito à determinação e à natureza do vínculo ou da relação entre os interessados.

O segundo elemento, objetivo, é caracterizado pela indivisibilidade do interesse ou direito. A impossibilidade de separação não está afeta ao elemento subjetivo, na medida em que não se exige vínculo direto e precedente entre as pessoas afetadas, até porque a presença de relação jurídica entre elas não existirá no caso dos interesses ou direitos difusos. Por outro lado, o vínculo de direito entre os interessados não constitui condição sine qua non para a caracterização do interesse ou direito como coletivo, em sentido estrito, na medida em que a relação pode ser, tão somente, com a parte contrária, nos termos da parte final do inciso II do parágrafo único do art. 81. Consequentemente, a indivisibilidade figura como qualidade do objeto que se quer buscar para a realização das necessidades, pertinentes à coletividade, ao grupo, categoria ou classe.

\section{A AÇÃO POPULAR NA ATUALIDADE: REFUTANDO ALGUNS MITOS}

A experiência da ação popular brasileira na tutela dos interesses transindividuais, na atualidade, é marcada por alguns mitos. Optou-se por se delimitar estes mitos a três, por serem os mais frequentemente referidos na prática, que serão abordados neste momento.

\section{O suposto insucesso das ações populares}

O primeiro que se destaca é a afirmação de que as ações populares, muitas vezes, são malsucedidas 
(GRINOVER, 2007, p. 807). Este argumento serve, inclusive, para defender a ilegitimidade do indivíduo para a tutela coletiva (MENDES; SILVA, 2013, p. 33-46), já que o cidadão é o legitimado apenas para a ação popular. Eurico Ferraresi destaca que o "brasileiro não está preparado para utilizar judicialmente as açôes coletivas"; e, caso fosse possível, poder-se-ia ter uma explosão de demandas, "sem relevância, o que retiraria força e credibilidade desse instrumento" (FERRARESI, 2009, p. 137).

Barbosa Moreira (BARBOSA MOREIRA, 2014, p. 30) já observava que a maioria dos casos de ação popular dizia respeito a atos economicamente lesivos, como a elevação irregular da remuneração fixada para exercício dos cargos públicos ou mandatos legislativos; concessão de benefícios ilegais a funcionários públicos e contratos administrativos em condições ilegitimamente onerosas para a Administração Pública, sendo que nem todas conduzem à procedência. De fato, há ações populares malsucedidas. Na época de sua pesquisa, muitas demandas já transitadas em julgado eram de improcedência e algumas demandas pendentes de julgamento do recurso também tinham sentença de procedência.

Atrelada a essa constatação, a produção doutrinária em torno da ação popular é bem mais escassa que a produção em torno da ação civil pública. Apenas para ilustrar, em consulta realizada ao acervo da Biblioteca Nacional em outubro de 2016, constavam 251 registros sobre ação popular, sendo que apenas 56 títulos são distintos sobre o assunto. Os demais ou representam uma edição atualizada da mesma bibliografia, ou não se referem a obras jurídicas ou, até mesmo, referem-se a outras disciplinas jurídicas. Sobre a ação civil pública são 356 registros na mesma biblioteca, sendo que 96 títulos são distintos sobre a ação civil pública.

Já na biblioteca do Superior Tribunal de Justiça (STJ), na mesma época, foram localizados 1.526 registros sobre o tema, muitos referentes, também, a uma edição mais atualizada da mesma obra, enquanto há 4.102 registros apenas sobre a ação civil pública, indicando uma produção bibliográfica e uma atualização das obras muito maior e muito mais frequente em se tratando desta.

Para agravar o panorama, alguns tribunais enfatizam a ação civil pública em detrimento de outras ações constitucionais. A título de exemplo, o Tribunal de Justiça do Estado do Rio de Janeiro (TJ/RJ) disponibiliza, em seu endereço eletrônico, através pesquisa por nome do réu, a busca apenas sobre as ações civis públicas, não abrangendo as ações populares.

Porém, tal como as demandas individuais ou as demais demandas coletivas, nem todas as ações populares ajuizadas são malsucedidas. Há demandas bem-sucedidas e outras que não seguem a mesma sorte, sem que seja possível generalizar. Divulgando dados sobre as ações populares em uma década, a Justiça Federal de São Paulo ${ }^{1}$ permite observar que, em 2000, foram 17 ações populares ajuizadas; em 2001 foram 8, mesmo número do ano de 2002; em 2003, foram 16 ações populares e, em 2004, foram 14 ações populares, números estes que se elevaram a partir de 2005: foram 33 ações populares em 2005; 41 em 2006; 40 em 2007; 60 em 2008; 33 em 


\section{9 e 38 em 2010.}

E não se trata apenas de números: algumas ações populares foram consideradas célebres ao longo de sua história, e eventual insucesso não a desqualifica. Barbosa Moreira (BARBOSA MOREIRA, 2014, p. 30-31) recorda a ação popular pleiteando a anulação do ato que aprovou a construção do aeroporto de Brasília, ao fundamento de que não se harmonizava com a estética da, na época, nova capital do país. Em outro caso, impugnaram-se atos administrativos relacionados ao aterramento parcial da Lagoa Rodrigues de Freitas, no Rio de Janeiro, para que fossem erguidos prédios, ao fundamento de que se desfiguraria local de excepcional beleza paisagística e, também no Rio de Janeiro, requereu-se a anulação de ato que permitiu a utilização de uma praça pública por associação carnavalesca para fins privados. Em São Paulo, ajuizou-se uma ação popular em face da demolição de estabelecimento de ensino e outra ação popular na estância hidromineral de águas de Lindóia, em face da construção de quiosques comerciais. Em Minas Gerais, foi ajuizada uma ação popular em face da Câmara Municipal, que autorizou, através de resolução, sem limites, a extração de madeira em floresta protetora de nascente de água utilizada para o abastecimento da população da cidade.

A Justiça Federal de São Paulo acrescenta a esse rol uma ação popular ajuizada em 1994, por quatro moradores do distrito da Lapa (zona oeste da capital), que transitou em julgado em 2011, com a condenação de 55 (cinquenta e cinco) vereadores paulistanos a devolverem aos cofres públicos parte dos salários que deveriam ter ido para o Imposto de Renda, o que pode chegar a 5,3 milhões para o erário. Trata-se de um exemplo latente de que nem toda ação popular é malsucedida.

Ademais, eventual suposto insucesso das ações populares é difícil até mesmo de ter sua existência aferida ou de ser quantificado na prática, diante da falta de dados unificados dos tribunais a respeito da ação popular. Caso ocorra, não é um demérito ao instituto, pelo contrário: é ocasionado pelo desconhecimento do direito, pelo aspecto psicológico, de quem pode estar em condições de inferioridade em face de seu adversário (MUNHOZ DA CUNHA, 1996, p. 250), com dificuldade especialmente para a produção de prova, e pelo distanciamento da coisa pública, que tornam a ação popular com pouca utilização na prática (GRINOVER, 2014, p. 43).

\section{A relevância da ação popular e a ação civil pública}

O segundo mito seria uma menor relevância da ação popular diante da ação civil pública, esta utilizada como referência nas ações coletivas. Eventuais ações populares malsucedidas não proporcionariam um cenário capaz de desqualificar a ação popular, de desfigurar a sua relevância na atuação cidadã, de participação direta na fiscalização da Administração Pública, única via de acesso à justiça do indivíduo na tutela coletiva atualmente admitida no ordenamento jurídico brasileiro.

A ação popular, no mesmo patamar da ação civil pública, é de extrema relevância para a tutela de direitos 
fundamentais, essencialmente difusos, incluindo o direito a uma administração pública proba, ao meio ambiente ecologicamente equilibrado e ao patrimônio histórico e cultural.

Ação popular e ação civil pública coexistem no ordenamento brasileiro, em uma relação de complementariedade de atuação entre os cidadãos, legitimados para a ação popular, e associações e órgãos públicos, legitimados para a ação civil pública, para possibilitar uma atuação plural quando o objeto das duas garantias se sobrepõe, sem qualquer exclusão (GARCIA, 2015, p. 27) e, acrescenta-se, sem prevalência de uma sobre a outra.

Sintetizando de forma precisa e brilhante o tema, o Ministro Luiz Fux, ainda no Superior Tribunal de Justiça, por ocasião do julgamento do REsp. 406.545/SP, em 26 de novembro de 2002, consignou que:

\begin{abstract}
a nova ordem constitucional erigiu um autêntico 'concurso de ações' entre os instrumentos de tutela dos interesses transindividuais e, a fortiori, legitimou o Ministério Público para o manejo dos mesmos. A ação civil pública não veicula bem jurídico mais relevante para a coletividade do que a ação popular. Aliás, a bem da verdade, hodiernamente, ambas as ações fazem parte de um microssistema de tutela dos direitos difusos onde se encarta a moralidade administrativa sob seus vários ângulos e facetas
\end{abstract}

\title{
A má-fé na ação popular
}

Por fim, o terceiro mito que se procura afastar é o de que as ações populares seriam instrumento usados de má-fé. Reforçar as sanções pela litigância de má-fé na ação popular, como forma de melhorar o seu desempenho, tal como pretendido pelo Projeto de Lei (PL) 265/2007, de autoria do Deputado Federal Paulo Maluf, também não parece ser o melhor caminho.

Aludindo a uma pesquisa empírica que analisou 179 ações populares no Tribunal de Justiça do Estado de Minas Gerais (TJ/MG) entre 01/07/2013 e 01/07/2014, constatou-se que em nenhuma ação popular houve litigância de má-fé (PAULA NETO, 2015, p. 256). Isso significa que, embora possa haver má-fé em algumas ações populares, a maioria não representa esta hipótese, mas os antigos problemas de desconhecimento deste instrumento, do próprio direito ou a insuficiência dos mecanismos previstos na Lei no 4.717/1965 para trazer o equilíbrio da relação processual, proporcionando isonomia entre autor e réu, em posições de desigualdade.

As afirmações em torno deste instrumento constitucionalmente assegurado precisam ser reanalisadas e revisitadas por estudos doutrinários comprometidos, além de ser necessário que adquiram um maior destaque na divulgação dos dados pelos tribunais.

\section{CONCLUSÃO}

A ação popular brasileira tem sua origem na Constituição de 1934, mas só veio a ser regulamentada em 1965, por ocasião da Lei no 4.717, com nítida ampliação do seu escopo. Ao longo de sua história, ocorreram 
conquistas para o fortalecimento deste instrumento, seja com o aumento dos entes que podem ter o seu patrimônio tutelado por esta via, seja em relação ao próprio patrimônio tutelável.

Parece, porém, que a ação popular brasileira em muito se afastou do berço deste instrumento em Roma. Além de a relação entre indivíduo e Estado ter conotação distinta, a sua tutela tinha eminentemente caráter penal, enquanto, no Brasil, seu cabimento é de natureza civil, essencialmente em relação aos direitos difusos, os quais se buscou problematizar.

No entanto, esta sua ampliação ainda esbarra em alguns mitos construídos acerca do tema, que tornam necessário estabelecer alguns pontos de inflexão para esta garantia constitucional no Brasil. As informações negativas divulgadas sobre a ação popular em nenhum momento desqualificam sua relevância enquanto instrumento de controle da Administração Pública por parte de seus cidadãos e da tutela de direitos fundamentais da coletividade. Ainda, sequer é possível afirmar que o uso da ação popular no Brasil é abusivo.

Trata-se de instrumento complementar à ação civil pública e que, eventual desempenho inferior a outras ações coletivas é atribuído muito mais ao desconhecimento do direito, ao distanciamento da coisa pública e ao desequilíbrio da relação processual. A litigância de má-fé pode ocorrer, como poderia em qualquer demanda, individual ou coletiva, mas também não é frequente.

A ação popular precisa adquirir maior atenção no ordenamento nacional e seu aprimoramento depende, apenas, de uma maior atenção da doutrina e dos tribunais, além de que se fortaleça, na sociedade, a educação política dos cidadãos e a transparência administrativa para a sua efetiva utilização em prol da tutela coletiva.

\title{
POPULAR ACTION IN BRAZILIAN LAW: FROM ITS SOURCE TO ITS ACTUAL INFLECTION POINTS
}

\begin{abstract}
The article analyzes popular action in the Brazilian legal system, from its origin to the present, when it emphasizes three points of inflection in the trajectory of this constitutional guarantee. It is sought to demonstrate, in its origins, how the Brazilian prediction moves away from the cradle of the institute, the roman actio popularis, and, at the present, it refutes the myths that popular actions would be unsuccessful; the instrument would be less relevant than the public civil action and that many popular actions are filed in bad faith.
\end{abstract}

Keywords: Popular Action; Historic; Transindividual Rights; Inflection Points. 


\section{REFERENCIAS}

ALMEIDA, Gregório Assagra. Manual das Ações Constitucionais. Belo Horizonte: Del Rey, 2007.

ALPA, Guido. Interessi Diffusi. Revista de Processo. São Paulo: RT, n. 81, jan.-mar. 1996, p. 146-159.

BARBOSA MOREIRA, José Carlos. A ação popular do direito brasileiro como instrumento de tutela jurisdicional. In.: GRINOVER, Ada Pellegrini et al. Processo Coletivo: do surgimento à atualidade. São Paulo: RT, 2014, p. 25-38.

Ações Coletivas na Constituição Federal de 1988. Revista de Processo. São Paulo: RT, N. 61, jan. - mar. 1991, p.187-200.

Temas de Direito Processual. São Paulo: Saraiva, Primeira Série, 1988.

CANOTILHO, J.J. Gomes; MENDES, Gilmar Ferreira; SARLET, Ingo Wolfgang; STRECK, Lenio Luiz (Coord. Científica). Comentários à Constituição do Brasil. São Paulo: Saraiva, 2014.

FERRARESI, Eurico. Ação popular, Ação Civil Pública e Mandado de Segurança Coletivo. Instrumentos Processuais Coletivos. Rio de Janeiro: Forense, 2009.

GARCIA, Emerson. Instrumentos de Defesa dos Direitos Fundamentais de Terceira Dimensão: a Funcionalidade da Ação Popular e da Ação Civil Pública. Revista de Processo. São Paulo: RT, vol. 243, mai. 2015, p. 17-36.

GRINOVER, Ada Pellegrini. A tutela jurisdicional dos interesses difusos. In.: GRINOVER, Ada Pellegrini et al. Processo Coletivo: do surgimento à atualidade. São Paulo: RT, 2014, p. 39-60.

et al. Código Brasileiro de Defesa do Consumidor. 9. ed. Rio de Janeiro: Forense Universitária, 2007.

Significado social, político e jurídico da tutela dos interesses difusos. Revista de Processo. São Paulo: RT, vol. 25, n. 97, jan-mar 2000, p. 9-15.

et al. Processo Coletivo: do surgimento à atualidade. São Paulo: RT, 2014.

LEONEL, Ricardo de Barros. Manual do Processo Coletivo. São Paulo: RT, 2002.

MANCUSO, Rodolfo de Camargo. Ação Popular. São Paulo: RT, 5.ed., 2003.

MAZZEI, Rodrigo; DAL 'COL; João Roberto de Sá. Ação Popular no Brasil e em Portugal. Revista de Processo. São Paulo: RT, vol. 240, fev. 2015, p.317-344.

MENDES, Aluisio Gonçalves de Castro. Ações coletivas e meios de resolução coletiva de conflitos no direito comparado e nacional. São Paulo: RT, 4.ed., 2014.

As perspectivas da tutela coletiva no Direito Processual. Jurispoiesis. Rio de Janeiro, v. 11, p. 29-54, 2008.

Do individual ao coletivo: os caminhos do direito processual brasileiro. Revista de Processo. São Paulo: RT, v. 165, p. 231-254, 2008.

MENDES, Aluisio Gonçalves de Castro; SILVA, Larissa Clare Pochmann da. A Legitimidade Ativa do Indivíduo nas Ações Coletivas. São Paulo: RT, jun. 2013, ano 38, vol. 220, p. 33-46.

Ações coletivas na jurisprudência do STJ. In.: GALLOTI, Isabel et al. O Papel da Jurisprudência no STJ. São Paulo: Revista dos Tribunais, 2014, p. 1.071-1.088. 
MENDES, Gilmar Ferreira; BRANCO, Paulo Gustavo Gonet. Curso de Direito Constitucional. São Paulo: Saraiva, 2014.

MILARÉ, Edis (coord.). Ação civil pública - Lei 7.347/85: reminiscências e reflexões após dez anos de aplicação. São Paulo: RT, 1995.

MUNHOZ DA CUNHA, Alcides A. Evolução das Ações Coletivas no Brasil. Revista da Procuradoria Geral da República. Brasília: ESMPU, n. 8, jan./jun. 1996, p. 246-258.

PAULA NETO, Joaquim José. A Ação Popular enquanto Instrumento de Controle da Administração Pública e o Denuncismo Irresponsável. Revista de Direito Constitucional e Internacional. São Paulo: RT, vol. 90, jan-mar. 2015, p. 247-264.

RAMOS, Elival da Silva. Ação popular como instrumento de participação política. São Paulo: RT, 1991.

SIDOU, J. M. Othon. Habeas corpus, mandado de segurança, mandado de injunção, habeas data, ação popular. 5.ed. Rio de Janeiro: Forense, 1998.

SILVA, Larissa Clare Pochmann da. A Legitimidade do Indivíduo nas Ações Coletivas. Rio de Janeiro: GZ, 2013.

Trabalho enviado em 02 de novembro de 2016.

Aceito em 16 de abril de 2017. 